\title{
The Coimbra University Hospital Experience in Liver Transplantation in Patients With Familial Amyloidotic Polyneuropathy
}

\author{
R. Perdigoto, A.L. Furtado, E. Furtado, F.J. Oliveira, B. Geraldes, O. Mota, J. Ferrāo, L. Tome, and \\ J. Viana
}

$\mathrm{F}$

AMILIAL amyloidotic polyneuropathy (FAP) is an inherited autosomal dominant systemic disease caused by an abnormal protein, the Transthyretin Methionine 30 (TTR Met 30, in the Portuguese variety methionine instead of valine). This abnormality is caused by a mutant gene in the 18th chromosome pair. The liver is the main site of production of the TTR Met 30 (more than 90\%), and the largest affected populations are located in Europe (Portugal and Sweden) and Asia (Japan). Nevertheless there are scattered cases all over the world. Usually the disease becomes clinically apparent in the third decade of life, especially for the Portuguese variety, and progresses to death in 10 to 14 years. ${ }^{1-5}$ Today liver transplantation is the only successful treatment for the disease. ${ }^{4-6}$ Furthermore, the livers from patients with FAP can be used with success for other patients awaiting a liver transplant, such as patients with liver tumors and/or cirrhosis. ${ }^{5}$ The neurological stage of the disease at the time of transplantation seems to be important for survival after the surgical procedure. ${ }^{6}$

\section{MATERIAL, METHODS, AND RESULTS}

We report our experience with liver transplantation in two populations of patients with FAP. Between November 1992 and April 2002, we performed transplantations on 143 patients in two different periods. The first period was between October 1992 and December 1995; the second period was from December 1995 to April 2002. The mean age of the 143 patients was 33 years (26 to 55). The distribution by gender was similar (Fig 1) In the first period included 49 patients (Group I) and the second period, 94 patients (Group II). The only difference between the two groups was the neurological stage of the disease at the time of transplantation. Patients who underwent transplantation in the first group had a higher incidence of disautonomy, malnutrition, and renal insufficiency. When compared with the patients of the second

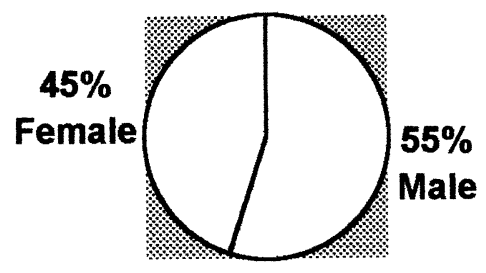

Fig 1. Gender distribution.

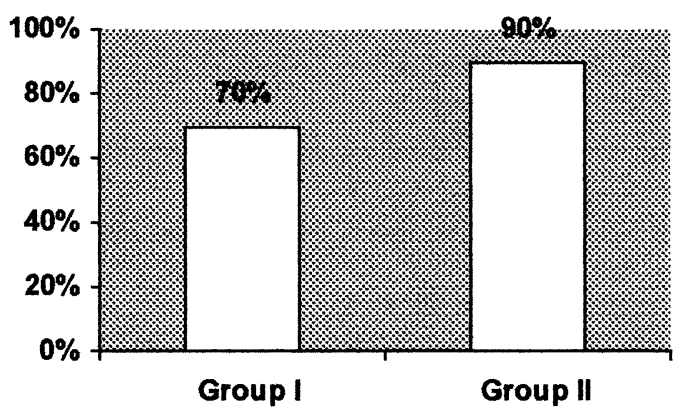

Fig 2. Survival of the two groups.

group, these patients had a significantly reduced survival rate (Fig 2) and a higher incidence of medical and surgical complications. However, both groups had similar incidences of rejection.

\section{DISCUSSION AND CONCLUSION}

Liver transplantation remains the only successful treatment to halt the progression of FAP. The selection of patients without advanced disease at the time of transplantation is important to improve survival after transplantation.

\section{REFERENCES}

1. Andrade C, Acta Neuropathol (suppl II):3, 1963

2. Saraiva MJM, Birken S, Costa PP, et al: J Clin Invest 74:104, 1984

3. Saraiva MJM, Costa PP, Goodman DS: J Clin Invest 76:2171, 1985

4. Holmgren G, Steen L, Ekstedt J, et al: Clin Genet 40:242, 1991

5. Furtado A, Tomé L, Oliveira FJ, et al: Transplant Proc 29:467, 1997

6. Monteiro E, Perdigoto R, Furtado AL: Hepato-Gastroenterology 45:1375, 1998

From the H.U.C./Unidade de Transplantação, Coimbra, Portugal.

Address reprint requests to R. Perdigoto, H.U.C./Unidade de Transplantação, 3000-075, Coimbra, Portugal. E-mail: ruiperdigoto@net.sapo.pt 